\title{
Hypoplastic posterior tibial artery and the enlarged peroneal artery supplying the posterior crural region: a rare variation
}

\author{
Artéria tibial posterior hipoplásica e a artéria peroneal aumentada \\ suprindo a região crural posterior: uma variação rara
}

\author{
Jiji P. J., ${ }^{1}$ Sujatha D'Costa, ${ }^{1}$ Soubhagya R. Nayak, ${ }^{1}$ Latha V. Prabhu, ${ }^{1}$ Mangala M. Pai, \\ Rajanigandha Vadgaonkar, ${ }^{1}$ Rajalakshmi Rai, ${ }^{1}$ Raju Sugavasi ${ }^{2}$
}

\begin{abstract}
Arterial variations of distal parts of lower extremities are well-documented and can be demonstrated with the help of Doppler ultrasound or by arteriography. However, absence or variation of posterior tibial artery is considered a rare finding. We present a case of hypoplastic posterior tibial artery that terminated by supplying soleus muscle. The variant arterial supply to the sole was provided by the enlarged peroneal artery that continued as the lateral plantar artery. The awareness of these variations is important to vascular surgeons while performing arterial reconstructions in femorodistal bypass graft procedures, and also to orthopedists during surgical clubfoot release.

Keywords: Arterial variations, posterior tibial artery, peroneal artery, soleus.
\end{abstract}

\section{Introduction}

Knowledge of anatomic variations in the branching pattern of the popliteal artery is important because damage to its branches can be limb-threatening. The two major variants in the popliteal branching pattern are its trifurcation (I-B) and high division with normal branching sequence (II-A) A category III, i.e., hypoplasticaplastic branching with altered distal supply, which is of greater clinical relevance to vascular surgeons, has been introduced recently. ${ }^{1,2}$

Normally, the popliteal artery divides into the anterior and posterior tibial (PT) arteries; but rarely it may bifurcate into anterior tibial (AT) and peroneal arteries (PR), the PT being absent or rudimentary. ${ }^{3-5}$ The incidence of hypoplastic-aplastic PT ranges between

\section{Resumo}

Variações arteriais de partes distais dos membros inferiores estão bem documentadas e podem ser demonstradas com o auxílio de ultra-sonografia Doppler ou por arteriografia. Entretanto, a ausência ou variação da artéria tibial posterior é um raro achado. Apresentamos um caso de artéria tibial posterior hipoplásica que terminava suprindo o músculo solear. Esse suprimento arterial variante foi fornecido pela artéria peroneal aumentada que continuava como artéria plantar lateral. Estar consciente dessas variações é importante para cirurgiões vasculares ao realizarem reconstruções arteriais em procedimentos de derivação femorodistal, bem como para ortopedistas durante correção cirúrgica do pé torto.

Palavras-chave: Variações arteriais, artéria tibial posterior, artéria peroneal, músculo solear.

$0.8-3.8 \%$ in the angiographic studies whereas in the anatomical studies it ranges between $1.5-11 \%{ }^{1-3,6-10} \mathrm{Com}-$ pensatory hypertrophy of the PR with a hypoplastic or aplastic PT or AT may indicate variant arterial supply to the foot. ${ }^{1}$ This enlarged PR, the "peronea magna" or "great" peroneal artery as described by Senior, either joins and reinforces the PT or replaces it in the distal leg and foot. ${ }^{4,5,11,12}$ When the peroneal replaces the PT on the ankle, the lower end of it is typically continued into the sole as the lateral plantar artery; the medial plantar is then usually absent. ${ }^{4,12}$

We present a case of the enlarged PR which continued as the lateral plantar artery of the sole and a rare hypoplastic PT represented by a muscular branch to soleus that arose from the PR. A similar case with PT represented by muscular branches to soleus was presented in the chapter on cardiovascular system of the

1. Department of Anatomy, Centre for Basic Sciences, Kasturba Medical College, Bejai, Mangalore, Karnataka, India.

2. Department of Anatomy, Rajiv Gandhi Institute of Medical Science, Cuddapah, Andhra Pradesh, India.

No conflicts of interest declared concerning the publication of this article.

Manuscript received Feb 18 2008, accepted for publication Apr 092008. 
Traite de l'Anatomie de l'Homme, by Bourgery and Jacob (1831) ${ }^{4,13}$ In addition, through the substance of tibialis posterior muscle (TP), the PR coursed for a short distance of $2 \mathrm{~cm}$ and there was no associated accessory flexor digitorum longus (FDL) muscle in contrast to the observation of Dobbs et al. but the flexor hallucis longus (FHL) was unusually bulky. ${ }^{14}$

\section{Case report}

The present variation was found during routine dissection of a male cadaver aged 68 years. It was present on the right side, and was unilateral. The popliteal artery, at the lower border of popliteus muscle, bifurcated into AT and PR (Figure 1A). The representative of PT was a muscular branch to soleus which arose $1.2 \mathrm{~cm}$ below the bifurcation, from the PR. At its formation, this deep sural artery was superficially crossed by the nerve to FDL, branch of tibial nerve (Figure 1B). Almost $10 \mathrm{~cm}$ distal to the point of bifurcation, after supplying the FDL, the PR entered the fascial canal between TP and FHL. It coursed within this fascial canal for $5.2 \mathrm{~cm}$, and further within the origin of TP for a short distance of 2 $\mathrm{cm}$ to lie behind the interosseus membrane, gave the perforator branch anteriorly near its exit from TP and then gave a lateral malleolar branch which farther gave many calcaneal branches. Passing deep to the tibial nerve and occupying the position medial to it and FHL tendon, the PR continued as the lateral plantar artery of the sole (Figure 2).

The PR had four medial and five lateral branches. All deep leg muscles were supplied by the PR. The nutrient artery to fibula was given while coursing within the substance of TP and the perforator branch to AT near its exit from TP.

\section{Discussion}

The awareness of the popliteal arterial variants is important for those performing surgical or percutaneous vascular reconstruction in the lower extremity. Distal popliteal arterial variations may influence the success of femorodistal popliteal and tibial arterial reconstructions. ${ }^{1}$ Senior explained the abnormal branching patterns of the popliteal artery as resultant of arrest of normal development of limb vessels. Briefly, the lower extremity vessels arise from two sources: the primary

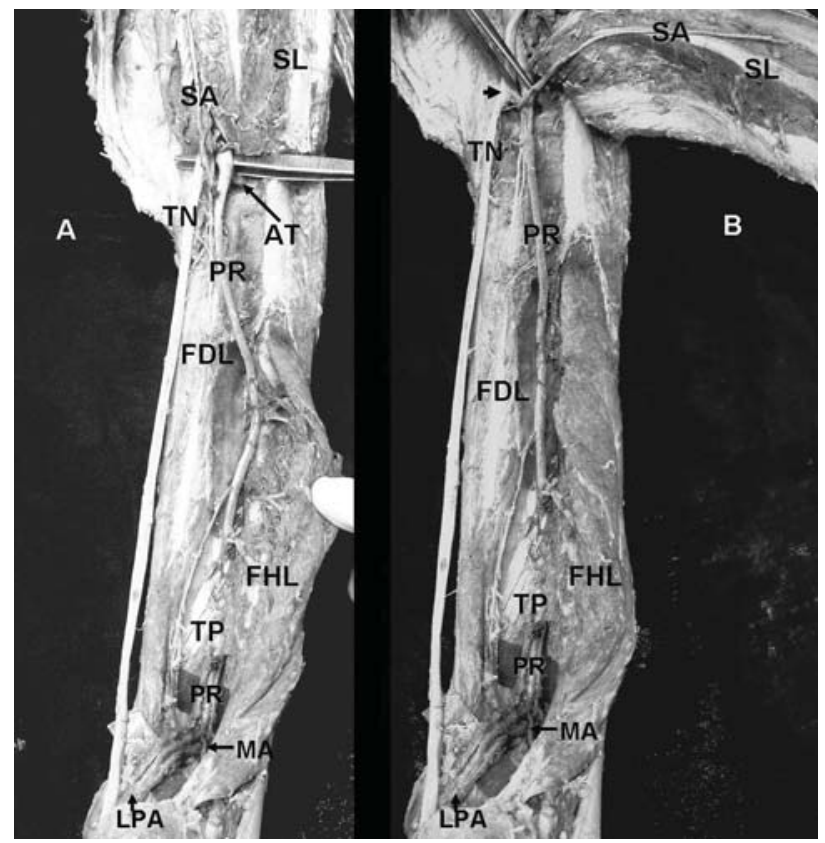

$\mathrm{AT}=$ anterior tibial artery $; \mathrm{FDL}=$ flexor digitorum longus $; \mathrm{FHL}=$ flexor hallucis longus; LPA = lateral plantar artery; MA = lateral malleolar artery; PR = peroneal artery; $\mathrm{SA}=$ sural artery; $\mathrm{SL}=$ soleus; $\mathrm{TN}=$ tibial nerve; $\mathrm{TP}=$ tibialis posterior.

Figure 1 - Deep structures of posterior leg compartment are revealed by reflecting the soleus muscle upwards and laterally and the tibial nerve medially: A) the popliteal artery entry site is deep to soleal arch, and its bifurcation to peroneal artery and anterior tibial artery are seen; B) clear indication of the origin of the nerve to flexor digitorum longus superficially crossing the origin of sural artery to soleus that represents the hypoplastic posterior tibial artery

limb bud artery (axial or sciatic artery, a branch of the umbilical artery), and the femoral artery. The popliteal and peroneal arteries arise from the axial artery, whereas the AT and PT derive from the femoral system. ${ }^{11}$ Being the derivative of the axial artery, the peroneal artery is constant and true absence of it has never been reported. ${ }^{12}$

The PT is often the main arterial supply to the foot in patients with clubfoot. Variations involving this vessel are of particular concern when these patients are managed surgically. ${ }^{14,15}$ Arteriographic studies revealed that the most common vascular abnormality associated with clubfoot has been absent AT, reported in up to $85 \%$ 


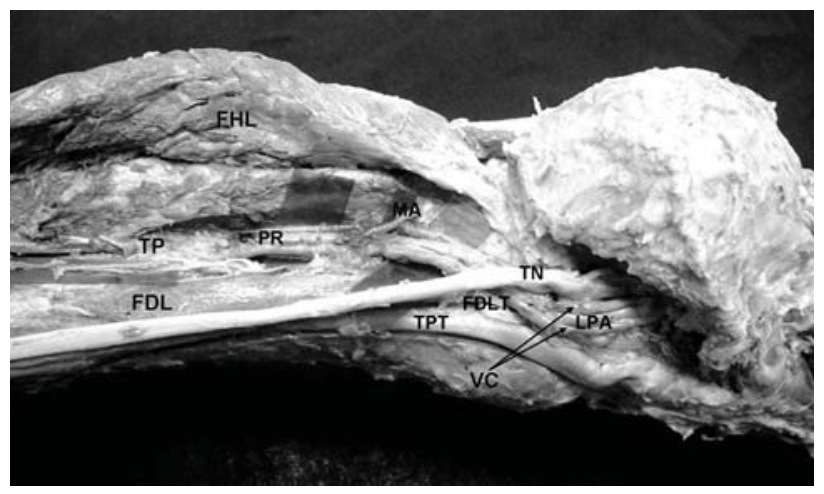

$\mathrm{FDL}=$ flexor digitorum longus; FDLT $=$ flexor digitorum longus tendon; FHL = flexor hallucis longus; $\mathrm{MA}=$ lateral malleolar artery; $\mathrm{TN}=$ tibial nerve; $\mathrm{TP}=$ tibialis posterior; TPT $=$ tibialis posterior tendon; $\mathrm{VC}=$ vena comitans.

Figure 2 - Structures passing beneath the flexor retinaculum to the sole: the photograph shows continuation of peroneal artery as lateral plantar artery of sole

of children with clubfoot. Hence, at the time of preoperative planning and surgical correction of clubfoot, it is best to assume the complete absence of the AT; consequently, great emphasis has been placed on protecting the PT and its terminal branch, the lateral plantar artery, during clubfoot release operations to prevent ischemia of the foot. ${ }^{16-18}$

The fibula with its peroneal vascular pedicle as a living bone graft is preferred in osseous reconstructions and in repair of extensive composite defects. The vascularization of fibula remains normal even in the absence of PT since the nutrient artery to fibula is provided by the PR. ${ }^{10}$ But harvesting of the peroneal artery in vascularized fibular grafting ${ }^{19}$ would be contraindicated in rare type III infrapopliteal patterns, particularly when the PR is the only artery to supply the foot. It may be necessary to modify the angioplasty technique to take account of the absence of vessels in order to minimize risk of complications. Although they represent a very small proportion of patients, the rare type III infrapopliteal patterns can have major implications in the surgical management of peripheral vascular diseases. ${ }^{2}$ Cognizance of important anatomical variations is a prime prerequisite for planning surgical and radiological interventions.

\section{References}

1. Kim D, Orron DE, Skillman JJ. Surgical significance of popliteal arterial variants. A unified angiographic classification. Ann. Surg. 1989;210:776-81.
2. Day CP, Orme R. Popliteal artery branching patterns--an angiographic study. Clin Radiol. 2006;61:696-9.

3. Quain R. Anatomy of the arteries of the human body. London: Taylor \& Walton; 1844. p. 538-43.

4. Senior HD. An interpretation of the recorded arterial anomalies of the human leg and foot. J Anat. 1919;53(Pt 2-3):130-71.

5. Gabella G. Cardiovascular system. In: Williams PL, Bannister LH, Berry MM, Collins P, Dyson M, editors. Gray's anatomy. 38th ed. London: Churchill Livingstone; 2005. p. 1502-3.

6. Dubreuil-Chambardel L. Variations des artères du pelvis et du membre inférieur. Paris: Masson; 1925. p. 240-3.

7. Adachi B. Das arteriensystem der Japaner. Kyoto: Maruzen; 1928. vol. 2, p. 196-242.

8. Bardsley JL, Staple TW. Variations in branching of the popliteal artery. Radiology. 1970;94:581-7.

9. Lippert H, Pabst R. Arterial variations in man: classification and frequency. München: JF Bergman Verlag; 1985.

10. Piral T, Germain M, Princ G. Absence of the posterior tibial artery: implications for free transplants of the fibula. Surg Radiol Anat. 1996;18:155-8.

11. Senior HD. The development of the arteries of the human lower extremity. Am J Anat 1919;25:55-94.

12. Hollinshead WH. Anatomy for surgeons. New York: Harper \& Row; 1969. vol. 3, p. 807.

13. Bougery, Jacob. Cardiovascular system. In: Traite de l'Anatomie de l'Homme. 1831.

14. Dobbs MB, Gordon JE, Schoenecker PL. Absent posterior tibial artery associated with idiopathic clubfoot. A report of two cases. J Bone Joint Surg Am. 2004;86-A:599-602.

15. Kitziger K, Wilkins K. Absent posterior tibial artery in an infant with talipes equinovarus. J Pediatr Orthop. 1991;11:777-8.

16. Greider TD, Siff SJ, Gerson P, Donovan MM. Arteriography in club foot. J Bone Joint Surg Am. 1982;64:837-40.

17. Edelson JG, Husseini N. The pulseless club foot. J Bone Joint Surg Br. 1984;66:700-2.

18. Sodre H, Bruschini S, Mestriner LA, et al. Arterial abnormalities in talipes equinovarus as assessed by angiography and the Doppler technique. J Pediatr Orthop. 1990;10:101-4.

19. Manaster BJ, Coleman DA, Bell DA. Magnetic resonance imaging of vascular anatomy before vascularized fibular grafting. J Bone Joint Surg Am. 1990;72:409-14.

\section{Correspondence:}

\section{P. J. Jiji}

Department of Anatomy, Centre for Basic Sciences, Kasturba Medical College

575004 - Mangalore, Karnataka - India

Tel.: +91 (824) 221.1746

Fax: +91 (824) 242.8183

E-mail: pj.jiji@gmail.com 